\title{
THE CORRELATION ACCREDITATION - BOLOGNA PROCESS - CONTINUOUS QUALITY IMPROVEMENT BASED IN PROFESSORS' PERCEPTIONS IN ALBANIAN PUBLIC UNIVERSITIES
}

\author{
Arjan Qefalia ${ }^{1}$ \\ Arbina Totoni ${ }^{2}$
}

\begin{abstract}
Quality is becoming a very important issue in higher education institutions toward gaining competitive advantage in this changing and dynamic environment. Bologna process seeking to unify or standardize the rules for higher education on the transfer of credits, free mobility of students and pedagogues etc, as well as the accreditation aiming quality assurance in higher education institutions, basically have as the main focus to improve the quality of universities in terms of teaching and on scientific research, which will make universities known. Nowadays, universities in developed and developing countries are using more and more continuous quality improvement methods, combined with the accreditation and implementation of the Bologna process, which constitutes the basis for ensuring the success of the these universities in the future. Even in Albania, universities are in a stage of continuous development by using many of the same continuous quality improvement methods like in western universities, are in a stage of accreditation and changing the curricula and the system according to Bologna Process.

In this paper, through the use of literature, the questionnaires and interviews directed mainly to the professors / pedagogues working in Albanian public universities, the focus is to show the importance of accredition and Bologna process for Albanian universities, the continuous quality imporovement methods used, and to test the hypothesis: The majority of professors / pedagogues think that the correlation between Accreditation - Bologna process - Continuous Quality Improvement is a strong positive correlation.
\end{abstract}

Key Words: Higher education, Continuous Quality Improvement, Bologna Process, Accreditation

JEL Codes: A22, A23, I23

\section{Introduction}

Quality itself, accreditation and implementation of the Bologna process aiming high quality, combined with the use of continuous quality improvement methods by universities, it constitutes the basis for ensuring the success of the higher education institutions.

Accreditation means giving a status that signals approval, sometimes a license to operate, a kind of formal recognition of a program or institution by an external body, based on an evaluation of its quality, and is based on predetermined standards (Van Damme, 2000). When applying accreditation mechanisms, this leads to a certain status associated with the capacity to offer different cycle diplomas, recognition of these diplomas from third parties, credits transfer to other accredited institutions, direct or indirect financing, and other external effects. In most cases, accreditation is the result of an evaluation or procedure of external quality assurance, evaluating whether a program or institution meets the academic or professional standards of the accreditation body. The accreditation process leads to a formal decision, which can be positive, conditional positive, or negative and based on clear minimal requirements. In general, the 'accredited' status is

\footnotetext{
${ }^{1}$ Tirana University, Faculty of Economy, Albania, email: arjan.qefalia@unitir.edu.al

${ }^{2}$ Tirana University, Faculty of Economy, Albania, email: arbina.totoni@unitir.edu.al
} 
given for a period of time (in the case of Albania is 6 years). A negative decision may be reviewed and procedures for reaccreditation can be done after a certain period of time. In the case of Albania, PAAHE (Public Accreditation Agency for Higher Education) is the responsible institution (public institution under the MoES - Ministry of Education and Science) for quality evaluation in higher education. Quality standards of accreditation can be placed at a minimum, as in the case of most accreditation procedures initiated by governments (or in higher levels), or when the status of accreditation is granted by professional organizations or academic networks (Van Damme, D., 2000).

Also, the Bologna process has the objective of increasing the international competitiveness of the European universities and points out the need to ensure that the European universities acquire a world-wide degree of attraction (ESU, 2009). The purpose of Bologna process and the accreditation and is to ensure the quality of the universities with the main focus 'student - the scientific community - the business community', and both relate to the focus of this study that is continuous quality improvement with its appropriate methods in order to return universities in competitive units to withstand constant changes that provides XXI century (ESU, 2009; Zgaga, 2003).

Higher education institutions to improve their selves, use CQI (Continuous Quality Improvement) methods like continuous improvement teams, benchmarking techniques, Balanced Scorecard method (Kaplan \& Norton, 2001), Baldrige National Quality Award and the European Quality Award, etc, where they can focus the improvement efforts on single areas or departments with shorter times for improvements (months rather than years). CQI use teams and other techniques to improve the efficiency and effectiveness of the processes, and to improve customer satisfaction (Cullen, et al., 2003). During last two decades, many $\mathrm{HEI}_{\mathrm{s}}$ (Higher Education Institution) began to implement new management approaches like TQM (Total Quality Management) or CQI, and many $\mathrm{HEI}_{\mathrm{s}}$ use American or European quality award criteria to improve their performance (Birnbaum, 2000; Mergen, et al., 2000).

Universities in Albania during these years are facing with many problems, but they can be considered normal in developing countries (Qefalia, Koxhaj, 2011). Also, it's supposed that the application of Bologna process should serve as an incentive to provide to higher education in Albania the full view of a priority sector of the economy. To make higher education institutions more efficient and effective in social and economic aspects, $\mathrm{HEI}_{\mathrm{s}}$ should be based on their effective strategy of continuous improvement. Accreditation by one side with a clear purpose to ensure quality in $\mathrm{HEI}_{\mathrm{s}}$, as well as the Bologna process which seeks to unify and standardize the rules for higher education regarding the credits transfer, free movement of students and professors / pedagogues etc; both in basically have the focus on improving the quality of universities in terms of teaching and on scientific research, which will make the universities known in the global arena (EUA, 2009).

In this paper there are taken into consideration only the public universities considering the fact that they have a teaching and research history, consolidated structures starting from the faculties, departments, together with the appropriate number of professors with proper qualifications. In the future, the focus will be extended even to private universities. By using the literature, questionnaires and interviews directed mainly to the professors / pedagogues working in Albanian public universities, fhe focus of this paper is to show the importance of accredition and Bologna process for Albanian universities, the continuous quality improvement methods used, and to test the hypothesis: The majority of professors / pedagogues think that the correlation between Accreditation - Bologna process - Continuous Quality Improvement is a strong positive correlation. This hypothesis is made to prove exactly how professors / pedagogues perceive this correlation, knowing that they are main stakeholders in this process (together with students). At the end of this paper, there're made conclusions and suggestions regarding this issue. 


\section{Research methodology}

Regarding research methodology, in this study there are used mainly qualitative methods, combined with quantitative research methods. There're used primary sources like interviews, questionnaires [distributed to professors / pedagogues working in Albanian public universities], and secondary sources (literature that exists regarding this managerial approach). In this paper it's used survey by choice (selection is random probability sample). There're collected 141 questionnaires completed by professors from higher education institutions throughout the Republic of Albania (taken under consideration 9 Albanian public universities, excluding the 3 academies), so the sample size was $\mathrm{n}=141$, and the selection covers a significant proportion the population $(\mathrm{n} / \mathrm{N}=$ $141 / 2,000=7 \%$ ), so the choice means a good representation of the population). Universities taken under consideration are the Tirana University, Polytechnic University, Agricultural University, Elbasan University, Shkodra University, Gjirokastra University, Korça University, Vlora University and Durrës University. It's used SPSS statistical program (the data are numbers) and to analyze the statistical indicators for the variables, it was proceeded with the Descriptive Analysis (Trochim, 2006).

\section{Accreditation of Albanian public universities}

Accreditation gives external recognition of quality for $\mathrm{HEI}_{\mathrm{s}}$, a quality that is highly desirable for the recognition of credits, diplomas, financing, and for obtaining legitimacy in the educational system, to employers, students, scientific community, society (citizens) and other stakeholders (ENQA, 2005). In exchange for the willingness of institutions to comply with high standards of quality assurance, governments in the following periods are trying to give more autonomy at the institutional level (this is part of their long term strategy; the same is for the strategy of Albanian universities). When institutions gain more autonomy, external accreditation, it is often seen as an affirmation of self-regulation capacity of the institution. In these circumstances, external accreditation becomes more important as for the mobility of students and teaching staff, and for the recognition of credits obtained between different universities.

Under the changes and reforms that have occurred in Albanian higher education to adapt to the requirements and European standards under the Bologna process, quality assurance in universities is one of the main elements of this reform (Qefalia, Rrumbullaku, 2010). The combination of internal evaluation with external evaluation of the $\mathrm{HEI}_{\mathrm{s}}$ is the indispensable tool for increasing quality. Institutions responsible for quality assurance in Albanian higher education are PAAHE and AC (Accreditation Council) in collaboration with MoES, and $\mathrm{HEI}_{\mathrm{s}}$ too. PAAHE has as its main responsibility the quality assessment in $\mathrm{HEI}_{\mathrm{S}}$ at institutional and/or program level. Internal evaluation (first phase) is carried out by own staff of $\mathrm{HEI}_{\mathrm{s}}$ and external evaluation (second phase) is performed by an external experts group for $\mathrm{HEI}_{\mathrm{s}}$ under evaluation; a process that is performed according to the criteria, procedures and guidelines developed by PAAHE and approved by the AC. The procedure for external evaluation is given in Fig. no. 1 (PAAHE, 2009).
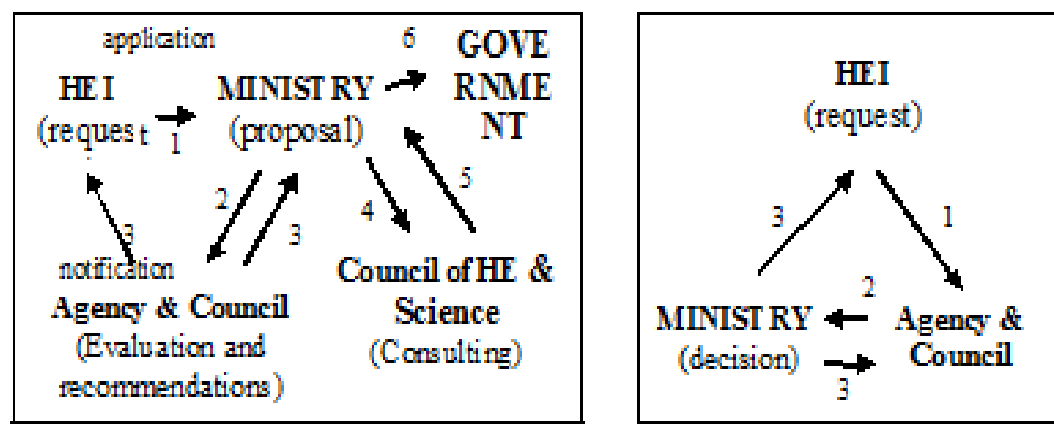

Fig. no. 1 - Procedure of external evaluation: ex-ante, first and periodical 
Source: PAAHE (2009). Annual Report on the PAAHE activities (Albania): External quality assurance in Albanian HE, p. 15-18.

\section{Evaluations made in Albanian HEI $_{\mathrm{s}}$}

PAAHE based in legal acts and other bylaws in the field of higher education has made evaluation of study programs applied by public $\mathrm{HEI}_{\mathrm{s}}$ as a result of reorganization of higher education studies based on the law no.9741, dated 21.5. 2007 'On Higher Education in the Republic of Albania' and the Bologna reform.

For more than a decade, the number of institutional and programs' evaluations in $\mathrm{HEI}_{\mathrm{s}}$ is growing, meaning that highest leaders of the universities are more conscious and aware regarding accreditation process. In Albania operates more than 47 higher education institutions public and private with a total of 950 programs offered by them; more specifically: 13 - Public $\mathrm{HEI}_{\mathrm{s}}, 5-\mathrm{HEI}_{\mathrm{s}}$ in Tirana, 6 - regional $\mathrm{HEI}_{\mathrm{s}}, 1$ - Military Academy, 1 - Albanological Academy, Total = 570 study programs; 45 - Private $\mathrm{HEI}_{\mathrm{s}}$ from which $35 \mathrm{HEI}_{\mathrm{s}}$ in Tirana; Total = 380 study programs (PAAHE, 2011).

During 2011, PAAHE has made the evaluation of new study programs, even estimates in the context of the accreditation process of private $\mathrm{HEI}_{s}$, cognitive activities and training for new evaluation criteria, etc (for more see Fig. no. 2). More specifically, the total number of new study programs (including three - study cycles) reviewed by PAAHE is 440 (174 public and 266 private) (PAAHE, 2011). Also, during 2011 there're completed institutional and program evaluations for seven new $\mathrm{HEI}_{\mathrm{S}}$ which are licensed or are in the licensing process.

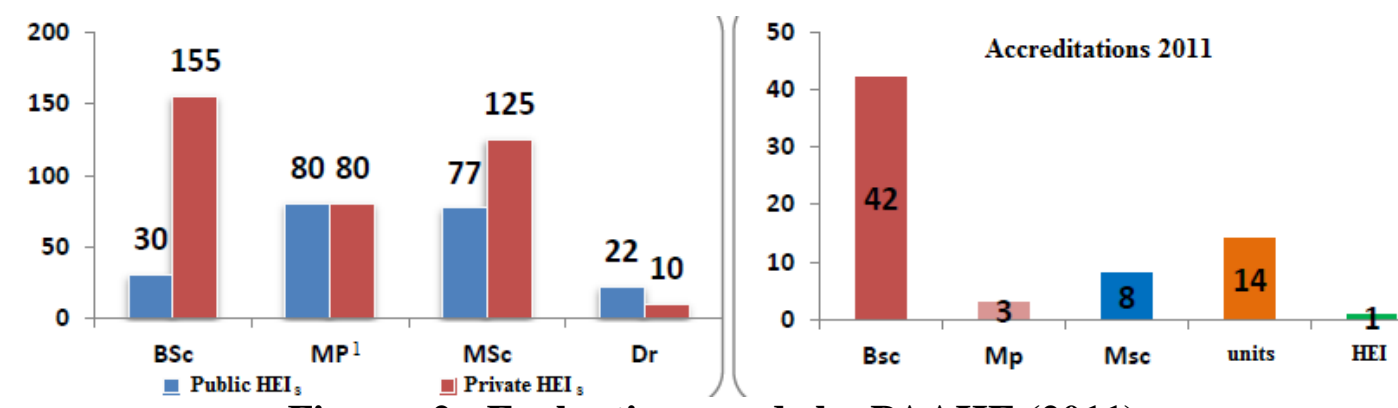

Fig. no. 2 - Evaluations made by PAAHE (2011)

Source: PAAHE Report, 2011 (MP': Professional Master). Self-Assessment Report of PAAHE (Albania), p. 78.

Regarding the tendency of evaluation in higher education, we can say that in the past was a tendency of the evaluation of programs at departmental level. Regarding the current situation, there's a shift in the intermediate (mixed) evaluation; initial evaluation is at program's level, followed then by periodic evaluation that focuses more on institutional evaluation and less on program level. Regarding the near future, there'll be an evaluation tendency mainly at the institutional level, but by focusing on Internal Quality Assurance.

\section{Bologna process and its importance}

Bologna process aims increasing the international competitiveness of the European universities and shows the need to ensure that the European universities acquire a world-wide degree of attraction (ESU, 2009). Bologna process seeks to unify and standardize the rules for higher education regarding the three cycle studies system, credits transfer, free movement of students and professors / pedagogues etc, focusing on improving the quality of universities in terms of teaching and on scientific research (Mikkola, et al., 2007). The purpose of Bologna process and the accreditation and is to ensure the quality of the universities with the main focus 'student - the scientific community - the business community', and both relate to the focus of this study that is continuous quality improvement with its appropriate methods in order to return universities in 
competitive units to withstand constant changes that provides XXI century (ESU, 2009; Zgaga, 2003).

Students are among the main stakeholders to be taken into consideration. They are the main customer of the service the higher education institutions offer. Students seek chances to be educated in a system with high standards equivalent in the regional market and broader. Higher education institutions should address questions like this: What are our products / services? Who are our customers? Who we are? and Which will be the future organizational issues and how they will be resolved?

Scientific Community. The role of scientific community is to make possible the achievement of the higher education institution's objectives regarding the Bologna process. Considering the fact that scientific community has the ability to develop new curricula, to create opportunities for students to develop research, it's the nation's cultural memory, it's the pride of generations; scientific community constitutes the basis to enable new developments in universities and to implement new approaches like Continuous Quality Improvement etc.

Business community is an important part because it employs graduates and finances many activities organized by higher education institutions and by the students. Universities must better serve the business community if they want to survive or to develop successfully in an environment that is becoming more competitive. There must be stimulated cooperation between universities and business community to achieve better results in: growth and improvement of the standards of higher education while at the same time in line with those objectives that higher education is charged by the Bologna process, qualified and capable work force, increase of the number of students in priority sectors such as tourism, exact sciences, industry etc.

What can be said is that Albanian public and private universities are making maximum efforts to adapt their systems and curricula in accordance with the requirements of the Bologna process. Such elements include three - cycle education system, creating credits system, and are making positive efforts to promote and facilitate the mobility of students and professors / pedagogues, and universities / faculties / departments are changing the way of management taking into account in their work the main stakeholders needs: students, scientific community and business community.

\section{CQI Methods used in Albanian public universities}

Continuous Quality Improvement methods that can be used by universities are:

Continuous Quality Improvement teams as CQI method means that employees' teams focus on a particular area (or different areas) for improvement within the organization (Goetsch \& Davis, 2010; Hill, 1997).

Benchmarking process as a CQI method makes the systematic identification of improvement areas and then compares the institution system with procedures used by the institutions or organizations 'best practice', from within or outside its industry, and by doing appropriate adjustments or arrangements (Goetsch \& Davis, 2010; Zairi \& Hutton, 1995).

Balanced Scorecard is a CQI method that uses a set of balanced goals and criteria to review business performance and to communicate when corrective actions are needed (Kaplan \& Norton, 2001). Considering that BSC (Balanced Scorecard method) method is conducted by the institution / organization strategy, it helps in communicating the mission, goals and objectives to all employees and other stakeholders.

Baldrige Quality Award and European Quality Award criteria regarding quality as CQI method can be used by $\mathrm{HEI}_{\mathrm{s}}$ to evaluate them related to the standards for excellent institutions. Considering continuous improvement process, the criteria for these awards focus on key areas like leadership, strategic planning, customer and market focus, measurement, analysis and knowledge management, human resources focus, process management, and institution performance (Goetsch \& Davis, 2010). 
From the questionnaire directed to professors / pedagogues working in Albanian public universities, 109 (out of 141) of them indicated that use CQI methods, and from the answers that listed a primary CQI method, 73 chose CQI teams, 34 chose Benchmarking techniques, only 2 chose BSC method and no one chose the method of different quality awards (see Fig. no. 3). In further analysis considering the use of CQI methods, this involves the use of CQI methods as in Fig. no. 3.

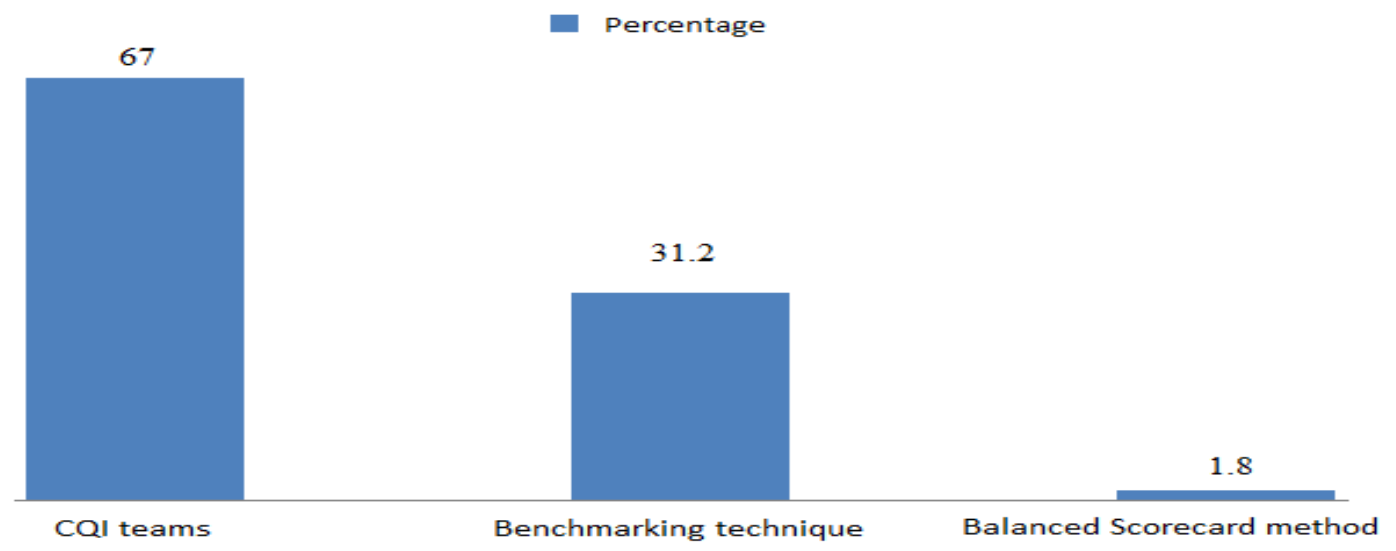

Fig. no. 3 - Frequency of the main method (in \%) used for CQI in universities / faculties / departments (from 109 users of CQI)

Source: The questionnaire - responses from the survey carried on by Authors (2011)

\section{The study of the positive correlation ${ }^{3}$ Accreditation - Bologna Process - Continuous Quality Improvement}

We discussed above regarding the accreditation, Bologna process and CQI methods that can be used to improve the quality of universities, but in this section will try to handle the perceived correlation of these elements from professors / pedagogues who are the main stakeholders in this process (together with students). To study this correlation, will be tested the following hypothesis, this depending on the perception of professors / pedagogues in Albanian public universities.

Hypothesis. The majority of professors / pedagogues think that the correlation Accreditation Bologna Process - Continuous Quality Improvement is a strong reciprocal correlation (Qefalia, 2010).

To prove this hypothesis it will be used the statistical test of hypotheses control of the proportion of a population (Lehmann, 1997). There's statistically strong correlation when $\mathrm{p} \geq 0.7$. Mark with $\overline{\mathrm{p}}$ - the proportion of professors / pedagogues who think that there's strong positive correlation (proportion of the choice).

There are taken under consideration 9 public universities in Albania (excluding 3 academies) with an approximate number of professors / pedagogues of 2,000 persons, therefore population in this survey is 2,000 persons. In this survey by choice, the selection is random probability sample. The number of respondents is 141 , so $n=141$ (see Table no. 1 for the survey data distribution regarding this question; from the analysis of Authors, 2011). Choice (in percentage) $=n / N=141 / 2,000=$ $7 \%$, so the choice means a good representation of the population. The confidence interval is $95 \%$ with error rate $\alpha=0.05$.

$\mathbf{H}_{\mathbf{0}}: \mathrm{p} \geq 0.7$. The majority of professors / pedagogues think that the correlation Accreditation Bologna Process - Continuous Quality Improvement is a strong positive correlation.

\footnotetext{
${ }^{3}$ According to professors / pedagogues' perceptions
} 
$\mathbf{H}_{\mathbf{a}}: \mathbf{p}<0.7$. The majority of professors / pedagogues doesn't think that the correlation Accreditation - Bologna Process - Continuous Quality Improvement is a strong positive correlation.

Hypothesis $\mathbf{H}_{\mathbf{0}}$ is rejected if $\mathrm{Z}$ observed $<-\mathrm{Z}_{\alpha}=-\mathrm{Z}_{0.05}=-1.64$ (value found from the normal distribution table) (Schervish, 1996).

$$
Z_{\text {observed }}=\left[\bar{p}-p_{0}\right] / S \bar{p}
$$

where, $\mathrm{p}_{0}$ - the proportion limit for being considered a strong correlation

$\mathrm{S}_{\overline{\mathrm{p}}}$ - standard deviation of the proportion

Table no. 1

The strength of positive correlation: Accreditation - Bologna Process -CQI

\begin{tabular}{|l|c|c|c|}
\hline & Frequency & Percentage & Cumulative percentage \\
\hline Limited & 11 & 7.8 & 7.8 \\
\hline Moderated & 16 & 11.3 & 19.1 \\
\hline Large & 114 & 80.9 & 100 \\
\hline \multicolumn{1}{|c|}{ Total } & 141 & 100.0 & 100.0 \\
\cline { 2 - 4 } & & &
\end{tabular}

Source: From the analysis of Authors (2011)

$\overline{\mathrm{p}} \quad=80.9 \%=0.809$ (the value which we're interested)

$\mathrm{p}_{0}=0.7$

$$
\mathrm{S}_{\overline{\mathrm{p}}}=[\overline{\mathrm{p}}(1-\overline{\mathrm{p}}) / \mathrm{n}]^{1 / 2} *[(\mathrm{~N}-\mathrm{n}) /(\mathrm{N}-1)]^{1 / 2}
$$

$\left.=[0.809(1-0.809) / 141]^{1 / 2} *[(2,000-141) /(2,000-1))\right]^{1 / 2}=0.0319$

From formula (1): $\quad Z_{\text {observed }}=\left[\overline{\mathrm{p}}-\mathrm{p}_{0}\right] / \mathrm{S}_{\overline{\mathrm{p}}}$

$=(0.809-0.7) / 0.0319=3.4169>-Z_{\alpha}=-Z_{0.05}=-1.64$, which means $H_{0}$ is not rejected, which means again to be proved the hypothesis expressed by the authors: "The majority of professors / pedagogues think that the correlation Accreditation - Bologna Process - Continuous Quality Improvement is a strong positive correlation”, with confidence interval 95\% and error rate $\alpha=0.05$. Now it can be said by the authors that the majority of professors / pedagogues in the population (Albanian public universities) as main stakeholders in this process, thinks that the correlation Accreditation - Bologna Process - Continuous Quality Improvement is a strong positive correlation with confidence $95 \%$

\section{Final results and conclusions}

Accreditation by one side with aiming to ensure quality in higher education institutions, as well as the Bologna process which seeks to unify and standardize the rules for higher education regarding the credits transfer, free movement of students and pedagogues etc., both in basically have as main focus quality improving of universities in terms of teaching and on scientific research, which will make universities known in the region and broader.

The purpose of accreditation and the Bologna process is to ensure the quality of the universities with the main focus 'student - the scientific community - the business community', which has never happened before this, and both are related to the focus of this study, using continuous quality improvement methods combined with the accreditation and Bologna process, in order to return to universities in competitive units to withstand the constant changes that provides XXI century. 
It is important to say that the Albanian public and private universities are making institutional and program's accreditation, are adjusting their systems and curricula according to Bologna process, and there are using CQI Methods.

Finally, what can be said is that CQI usage is correlated to accreditation and the Bologna process. Any changes to each element, significantly affects to other elements. This hypothesis was proved by the authors that the majority of professors / pedagogues (as main stakeholders in this process) think that the correlation Accreditation - Bologna Process - Continuous Quality Improvement is a strong positive correlation with confidence $95 \%$.

\section{Further directions of research}

In this study it was proved the strong positive correlation Accreditation - Bologna Process Continuous Quality Improvement based in professors' perceptions in Albanian public universities, although we all are aware that no research study can answer all the questions regarding a particular theme. An area for further study would be that of using specific quantitative and qualitative data regarding the implementation and results of CQI users: Albanian public and private universities. Another area would be studying the accreditation impact in improving the quality in Albanian higher education institutions. Also, another area for further research would be that of using specific qualitative and quantitative data regarding the implementation and results of Bologna Process, and its impact in improving the Albanian universities and in transforming them into competitive units in the region and broader.

\section{References}

1. Birnbaum R., 2000. The life cycle of academic management fads. Journal of Higher Education, 71(1), 1-16.

2. Cullen J., Joyce J., Hassall,T., Broadbent M., 2003. Quality in higher education: From monitoring to management. Quality Assurance in Education, 11(1), 5-14.

3. ENQA, 2005. Standards and Guidelines for Quality Assurance in the European Higher Education Area. European Association for Quality Assurance in Higher Education, Helsinki

4. ESU, 2009. Bologna with Student Eyes - Enhancing the Student Contribution to Bologna Implementation. ESCBI - project funded by the European Commission.

5. EUA, 2009. Improving quality, enhancing creativity: Change processes in European higher education institutions., available online at http://www.eua.be/Publications.aspx

6. Goetsch D. L., Davis, S. B., 2010. QM for organizational excellence. (6 ${ }^{\text {th }}$ ed.),

7. Hill F. M., 1997. En route to TQM: Organizational learning through quality circles. Training for Quality, 5(2), 84-87.

8. Kaplan R. S., Norton D. P., 2001. The strategy focused organization: How balanced scorecard companies thrive in the new business environment (1st Ed. ed.)., Boston: Harvard Business School Press.

9. Law no.9741/21.5.2007, For higher education in the Republic of Albania

10. Lehmann E. L., 1997. Testing Statistical Hypotheses: The Story of a Book, Statistical Science 12 (1), p. 48-52.

11. Mergen E., Grant D., Widrick S. M., 2000. Quality management applied to higher education. Total Quality Management, 11(3), 345-352.

12. Mikkola A., Carapinha B., Tuck C., MacSithigh D., Aberg G. Nina., Brus S., 2007. Bologna with Students Eyes - ESIB: The National Unions of Students in Europe: p. 3-70.

13. PAAHE, 2009. Annual Report on the PAAHE activities (Albania): External quality assurance in Albanian HE, p. 15-18, available online at www.aaal.edu.al 
14. PAAHE, 2011. Self-Assessment Report of PAAHE (Albania), p. 7-8, available online at www.aaal.edu.al

15. Qefalia A., 2010. Management and Continuous Quality Improvement in Albanian Public Higher Education, PhD thesis, Tirana University, Albania.

16. Qefalia A., Rrumbullaku O., 2010. Accreditation impact in assuring and continuous quality improvement in Albanian higher education, Economic \& Social Challenges and Problems Facing impact of global crisis, International Conference in Tirana, Albania

17. Qefalia A., Koxhaj A., 2011. The use of continuous improvement in Albanian public higher education, The Romanian Economic Journal, Year XIV, no. 41.

18. Schervish M., 1996. Theory of Statistics, Springer, p. 218.

19. Trochim William M. K., 2006. Descriptive statistics - Research Methods Knowledge Base. Web Center for Social Research Methods. Available online at www.socialresearchmethods.net/kb/statdesc.php.

20. Van Damme D., 2000. Accreditation in global higher education. The need for international information and cooperation. Outline of a IAUP approach, Memo for the Commission on Global Accreditation of the International Association of University Presidents, p.1-13.

21. Zairi M., Hutton R., 1995. Benchmarking: A process-driven tool for quality improvement. The TQM Magazine, 7(3), 35-40.

22. Zgaga P., 2003. Bologna Process between Prague and Berlin, Follow-up Group of the Bologna Process, p.4-115. 